Bangladesh J. Bot. 42(1): 31-43, 2013 (June)

\title{
ALLEVIATION OF SEA WATER STRESS ON TOMATO PLANTS BY FOLIAR APPLICATION OF ASPARTIC ACID AND GLUTATHIONE
}

\author{
Samia Ageeb Akladious* and Salwa Mohamed Abbas \\ Department of Biological and Geological Sciences, Faculty of Education, \\ Ain Shams University, El Makres St. Roxy, Cairo, Egypt, P.O.Box 1575
}

Key words: Alleviation, Amino acids, Glutathione, Lycopersicon esculentum, Salinity

\begin{abstract}
Tomato plants (Lycopersicon esculentum Mill.) treated with 8 and $16 \%$ of sea water reduced growth parameters and chemical constituents. Both aspartic acid and glutathione increased plant growth, anthocyanin, $\alpha$-tocopherol, ascorbic acid and enzymatic activities. Increased endogenous amino acids led to positive changes in protein electrophoresis and caused obvious changes in anatomical features of the stems. The effect of aspartic acid was superior to that of glutathione in increasing plant growth. Under low saline conditions, maximum plant growth was obtained from plants treated with aspartic acid and $8 \%$ of sea water, followed by $4 \%$. Data revealed that antioxidants could partially alleviate the harmful effects of salinity.
\end{abstract}

\section{Introduction}

Soil salinity is an abiotic stress and limiting factor for plant production. Increasing $\mathrm{NaCl}$ concentration in nutrient solution adversely affected tomato shoot and plant height, $\mathrm{K}$ concentration and $\mathrm{K} / \mathrm{Na}$ ratio (Garcia et al. 2007). Salt stress causes partial swelling of endoplasmic reticulum, decrease in mitochondrial cristae and swelling of mitochondria, fragmentation of tonoplast and degradation of cytoplasm by the mixture of cytoplasmic and vacuolar matrices in leaves of sweet potato (Mitsuya et al. 2000). The important response of salt stress is reduction in the rate of leaf surface expansion leading to cessation of expansion as salt concentration increases. Salt stress causes water deficit as a result of osmotic effects on metabolic activities of plants and this water deficit results in oxidative stress because of the formation of reactive oxygen species. The reactive oxygen species that are by products of hyperosmotic and ionic stresses cause membrane disfunction and cell death. The most common stress responses in plants is overproduction of compatible organic solutes which are low molecular weight, highly soluble compounds that are usually nontoxic at high cellular concentrations. The plants defend against these reactive oxygen species by induction of activities of certain antioxidative enzymes such as catalase, peroxidase, glutathione reductase, and superoxide dismutase, which scavenge reactive oxygen species. Activities of antioxidative enzymes increase under salt stress in wheat (Hernandez et al. 2000).

The asparagine and glutamine connect the two important metabolic cycles of the plant, the carbon and nitrogen cycles, and they have an influence both on sugars and proteins. In plants, aspartate is the precursor to several amino acids, including methionine, threonine, isoleucine (Rawia et al. 2011). Glutathione (GIT) is non-protein thiol present in plants. The alleviating effect of glutathione might be through scavenging active oxygen species under salt stress.

The aim of present work is to increase the salinity tolerance by treatment with glutathione and aspartic acid in tomato plants grown under higher level of salinity.

*Author for correspondence: <samiapola@yahoo.com>. 


\section{Materials and Methods}

Tomato-super strain B- (Lycopersicom esculantum Mill., Castle rook cultivar) seeds were obtained from the Vegetables Research Center, El-Dokkey, Giza, Egypt. The seeds were surface sterilized by immersing in $70 \%$ ethanol for $2 \mathrm{~min}$ followed by $0.2 \%$ sodium hypochlorite $(\mathrm{NaOCl})$ for $3 \mathrm{~min}$. They were washed for several times with sterile distilled water, and then grown in large clay pots ( $40 \mathrm{~cm}$ diam) containing loam based garden soil and were divided into two groups. The 1 st group of pots was irrigated with tap water to serve as control. The 2 nd group was irrigated with tap water until the 3-leaf stage appeared then they were divided into three sets and irrigated with three salinity treatments. The sea water salinity was prepared by diluting sea water brought from the Mediterranean Sea, near Alexandria city (the major ions of sea water were: $487 \mathrm{mM} \mathrm{Na}^{+}, 10$ $\mathrm{mM} \mathrm{K}^{+}, 54 \mathrm{mM} \mathrm{Mg}^{2+}, 586 \mathrm{mM} \mathrm{Cl}$, plus other less concentrated macro- and micro-nutrients) to obtain three concentrations $(4,8$ and $16 \%)$ using electrical conductivity meter. Plants were watered with equal amounts of the suggested concentrations of the sea water to maintain soil moisture near field capacity. At 5-leaf stage, some pots from each group was sprayed with 20 $\mathrm{ml} / \mathrm{plant}$ of two different solutions namely aspartic acid in concentration of $100 \mathrm{mg} / \mathrm{l}$ and glutathione in concentration of $50 \mathrm{mg} / \mathrm{l}$ glutathione. Spraying treatments were carried out two times with two weeks interval for both spraying treatments. Plant samples were harvested 10 weeks after sowing date (70 days old). Leaves, stems and roots were separated for analysis.

Plant height, number of leaves, leaf area, fresh weight and dry matter of shoot and root were determined for each treatment. Anthocyanin content was estimated after Krizek et al. (1993). The content of $\alpha$-tocopherol was measured following Philip et al. (1954). Ascorbic acid was determined as described by Mukherjee and Choudhuri (1983). Catalase (CAT), peroxidase (POX) and polyphenol oxidase (PPO) activities were assayed according to Kumar and Khan (1982). Electrophoretic protein profile of tomato leaves was analyzed according to SDS-PAGE technique (Laememli 1970) which relates polypeptide maps, molecular protein markers, percentage of band intensity using gel protein analyzer version 3 (MEDIA- CYBERNE TICE, USA). Acid hydrolysis and HPLC determination of amino acids were carried out after Gehrke et al. (1985). Anatomical studies were carried out by using the method of Nassar and El-Sahhar (1998). The sections were examined to detect histological manifestations of noticeable responses resulting from the treatment of the plants.

The results were subjected to one-way ANOVA and the differences between means at the 5\% probability level were determined using DMRT.

\section{Results and Discussion}

Irrigation of tomato plant with sea water revealed that plant height, number of leaves/plant, root length, leaf area, as well as fresh and dry weights of the different plant parts declined with increasing sea water (SW) concentrations as compared with control (Table 1). However, foliar spraying of plants with aspartic acid or glutathione increased these growth parameters of plants grown under either non saline or saline conditions compared with control. The inhibitory effects of salt stress on these growth parameters were also recorded by other investigators in various plant species (Hassanein et al. 2008, Wahba et al. 2002).

Salt stress had an inhibitory effect on the ancothyanin, $\alpha$-tocopherol and ascorbic acid contents in the tomato plants, these contents were significantly decreased in the stressed plants (Table 2). On the other hand, data shows that foliar spraying of the plants with AA and/or GIT significantly increased the contents of anthocyanin, $\alpha$-tocopherol and ascorbic acid particularly under saline conditions ( 4 and $8 \%$ ) as compared with control. Salt stress accelerates the formation of Reactive Oxygen Species (ROS). Plants maintain complex systems of multiple types of 


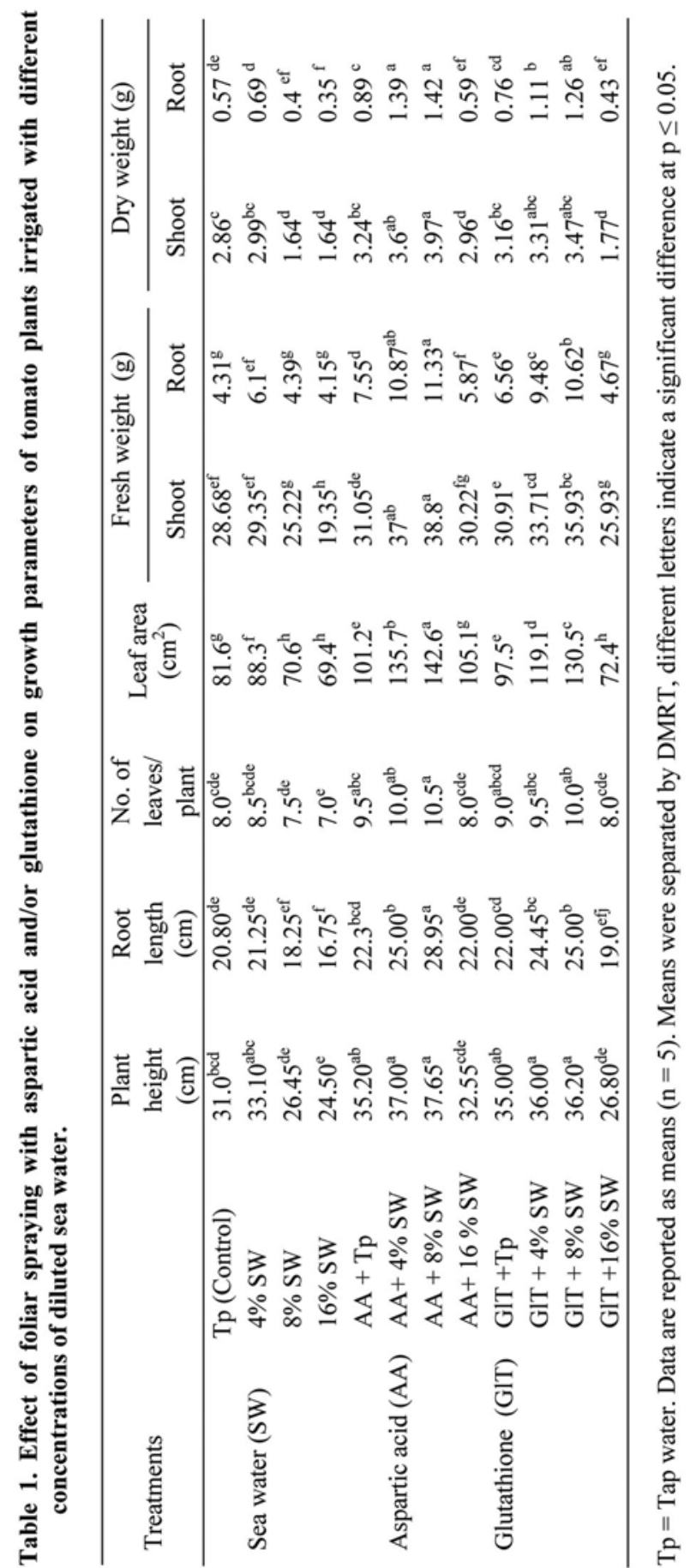




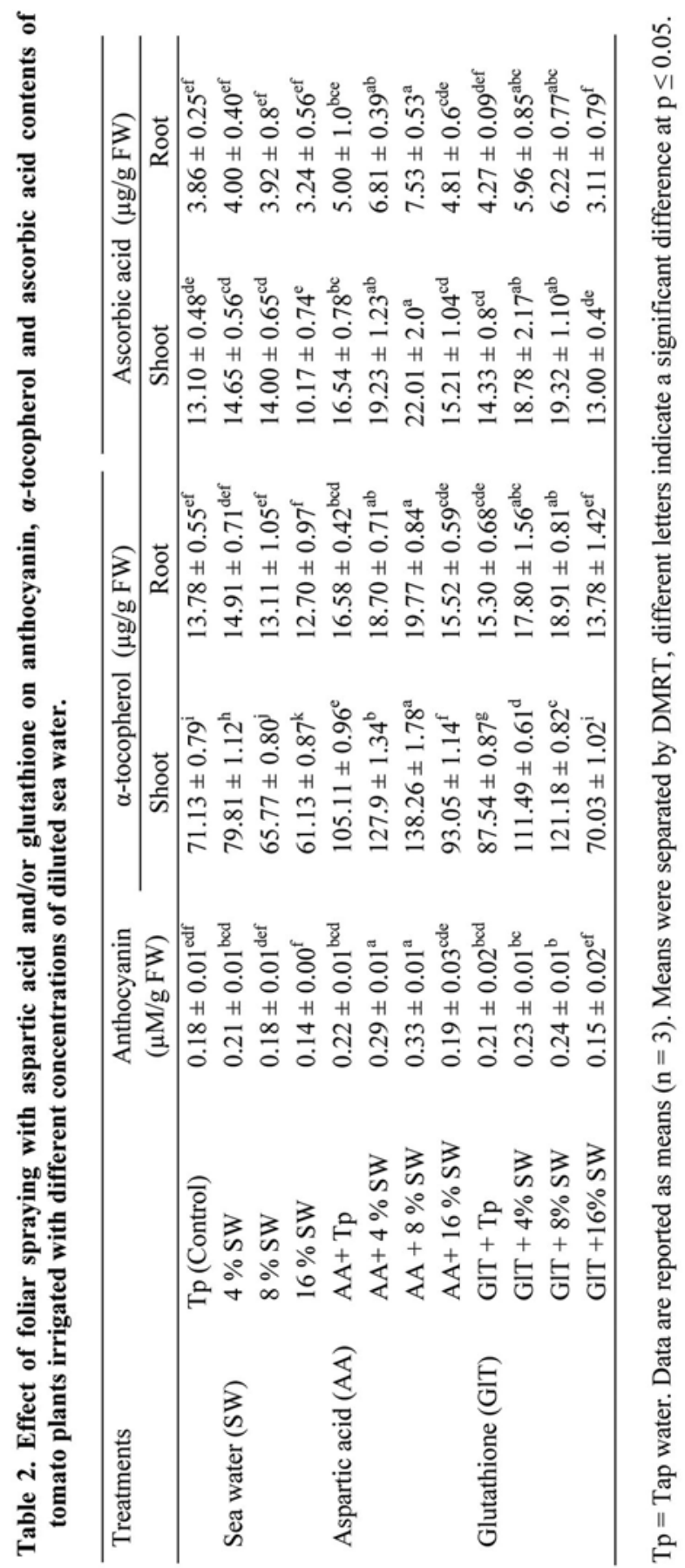


antioxidants, such as anthocyanin, ascorbic acid (vitamin C) and tocopherol (vitamin E). Nonenzymatic antioxidant activity is represented by a series of antioxidant molecules that the plant uses against active oxygen species formation (Mittler 2002).

The changes in various enzyme activities of shoot and root of tomato plants in response to salinity stress either alone or in combination with aspartic acid and/or glutathione are shown in Figs 1 - 3. Results indicated that peroxidase (POX), catalase (CAT) and polyphenol oxidase (PPO) activities were significantly decreased in shoot and root of tomato plants irrigated with different concentrations of sea water (SW). On the other hand, tomato plants treated with AA and/or GIT exhibited more stress resistance by increasing their activities of CAT, POX and PPO as compared
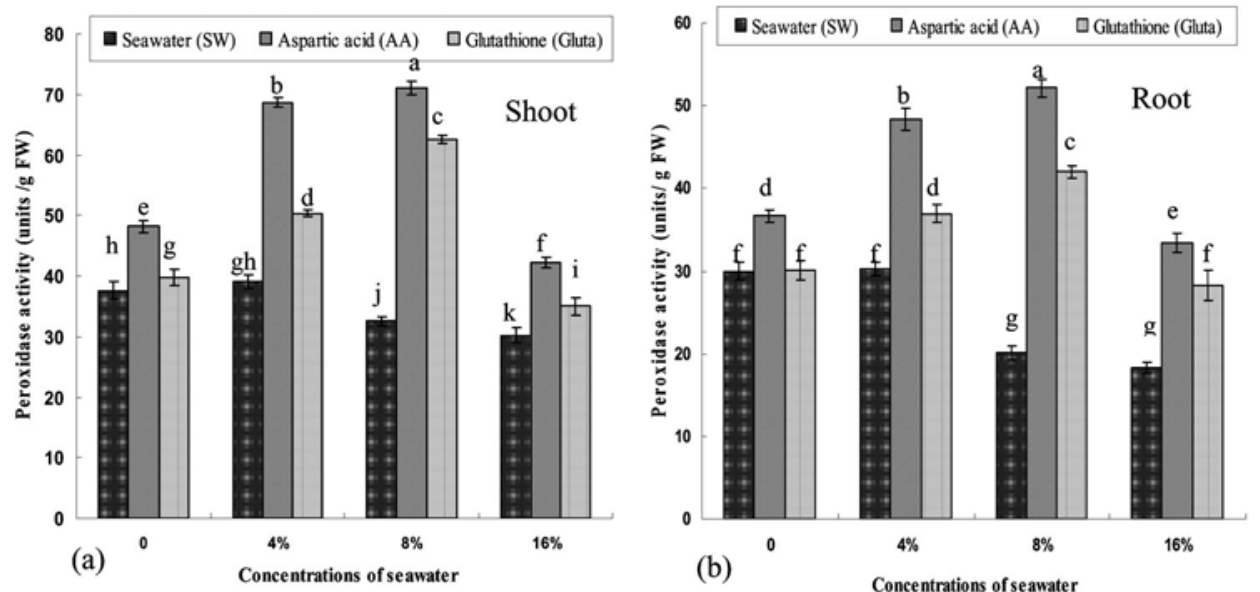

Fig.1a-b: Effect of foliar spraying with aspartic acid and/or glutathione on peroxidase activity of shoot (a) and root (b) of tomato plants grown under saline conditions. Bars represent the means $\pm \mathrm{Sd}$.
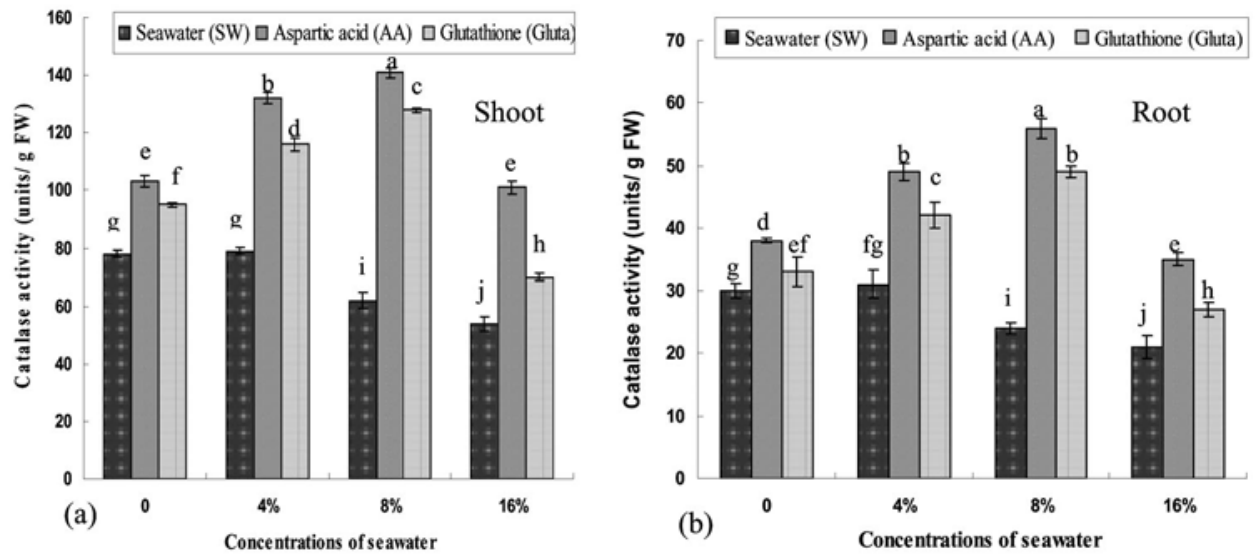

Fig. 2a-b: Effect of foliar spraying with aspartic acid and/or glutathione on catalase activity of shoot (a) and root (b) of tomato plants grown under saline conditions. Bars represent the means $\pm \mathrm{Sd}$.

with untreated plants. The higher activities in these enzymes were recorded in plants treated with AA and irrigated with $8 \% \mathrm{SW}$. The reduction in these enzymes activities as a result of salt stress demonstrated that these enzymes were unable to completely neutralize $\mathrm{H}_{2} \mathrm{O}_{2}$ resulted from the oxidative salt stress. Dash and Panda (2001) reported that higher activity of antioxidant enzymes 
(CAT, POX and PPO) caused lower $\mathrm{H}_{2} \mathrm{O}_{2}$ production, lipid peroxidation and higher membrane stability. These enzymes are involved in reelimination of $\mathrm{H}_{2} \mathrm{O}_{2}$ from stressed cells. Catalase is the most effective antioxidant enzyme preventing oxidative damage. Exogenous application of either AA or GIT significantly increased the specific activity of phenol peroxidase in the stressed plants, which decreased the injurious effect of salt and it reacted with $\mathrm{H}_{2} \mathrm{O}_{2}$ and maintained the membrane integrity (Sairam et al. 2005).
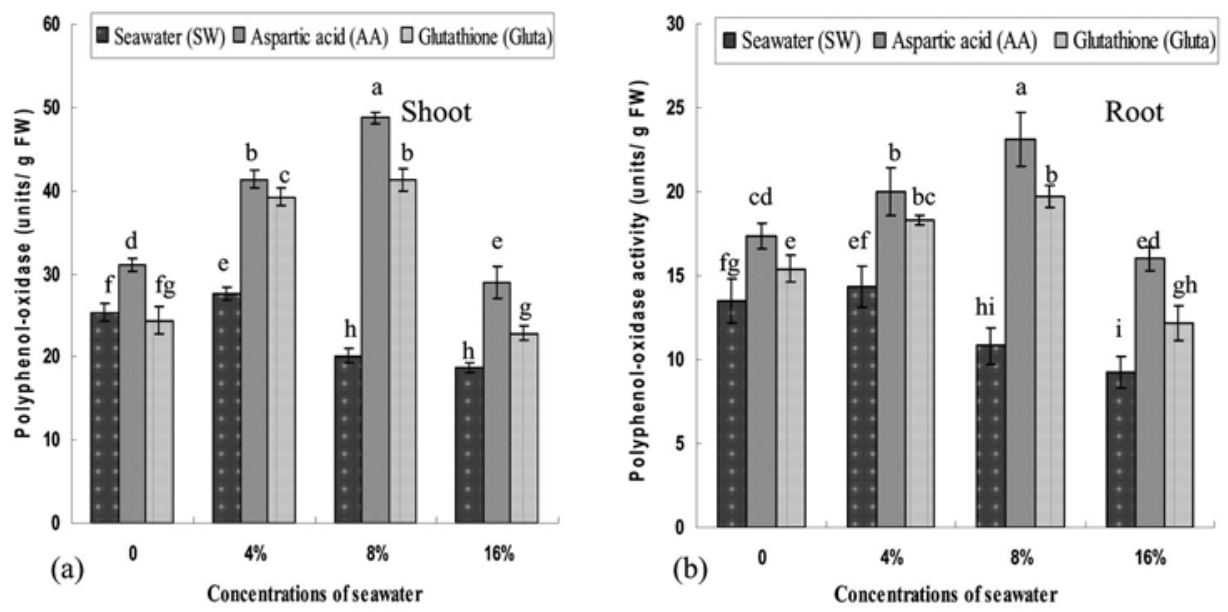

Fig. 3a-b: Effect of foliar spraying with aspartic acid and/or glutathione on polyphenol-oxidase activity of shoot (a) and root (b) of tomato plants grown under saline conditions. Bars represent the means $\pm \mathrm{Sd}$.

Different SDS-PAGE patterns of tomato plants irrigated with different levels of salinity $(4,8$ and $16 \%$ ) and foliar spraying with aspartic acid and/or glutathione are presented in Table 3 and Fig. 4. Irrigation of tomato plants with different sea water (8 and 16\%) levels showed an increase in the total number of protein bands. In addition, tomato plants irrigated with different levels of salinity and foliar spraying with aspartic acid and/or glutathione exhibited an increasing in the total number of bands. These results indicate that the plant irrigated with different salinity levels plus application of glutathione and aspartic acid characterized by the appearance of new bands as compared with that of the untreated plants. Scanning of the gel showed that the protein band which has the molecular weight (MW) of $164.17 \mathrm{kDa}$ disappeared under saline conditions. At the same time 4 bands with MWs of 54.12, 31.95, 28.50 and 19.28 kDa have developed in plants treated with different levels of salinity alone or with salinity levels plus sprayed by the two used antioxidants but these bands were not detected in the control plant. Foliar spraying of tomato with aspartic acid only induced the appearance of two newly protein bands at MWs of 202 and 17.96 $\mathrm{KDa}$. Whereas, the protein band which has the MWs of $21.84 \mathrm{kDa}$ characterized the plants treated with salinity levels and glutathione. These results confirmed the results reported by El-Bassiouny et al. (2008) who concluded that one of the important mechanism involved in the cell protection against salinity stress is the induction of de novo synthesis of a set of new protein. The salinity altered the protein patterns of two Anabaena strains by inducing the synthesis of a specific of proteins called the salt-stress proteins that are strain dependent (Apte and Bhagwat 1998). 


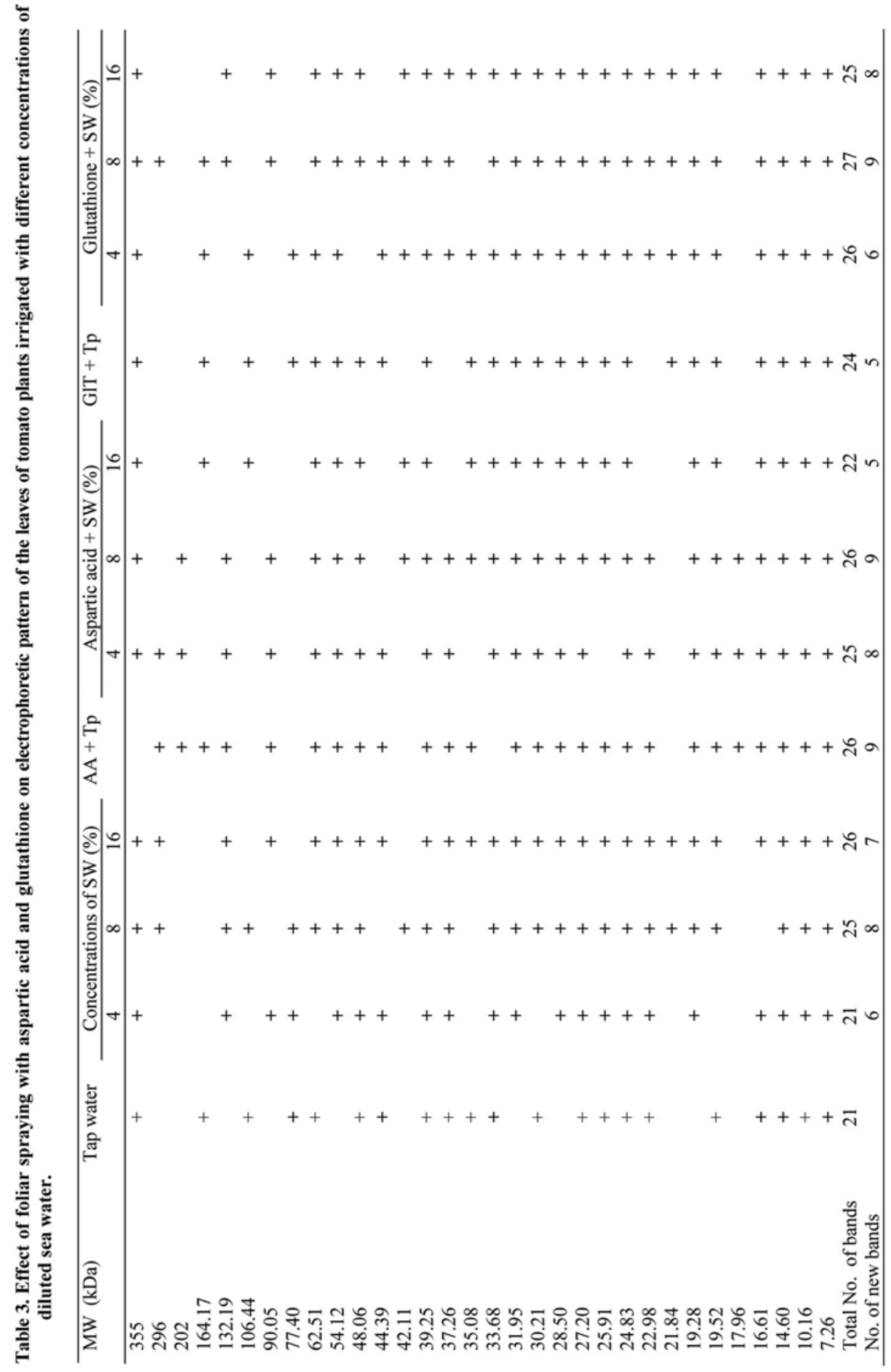




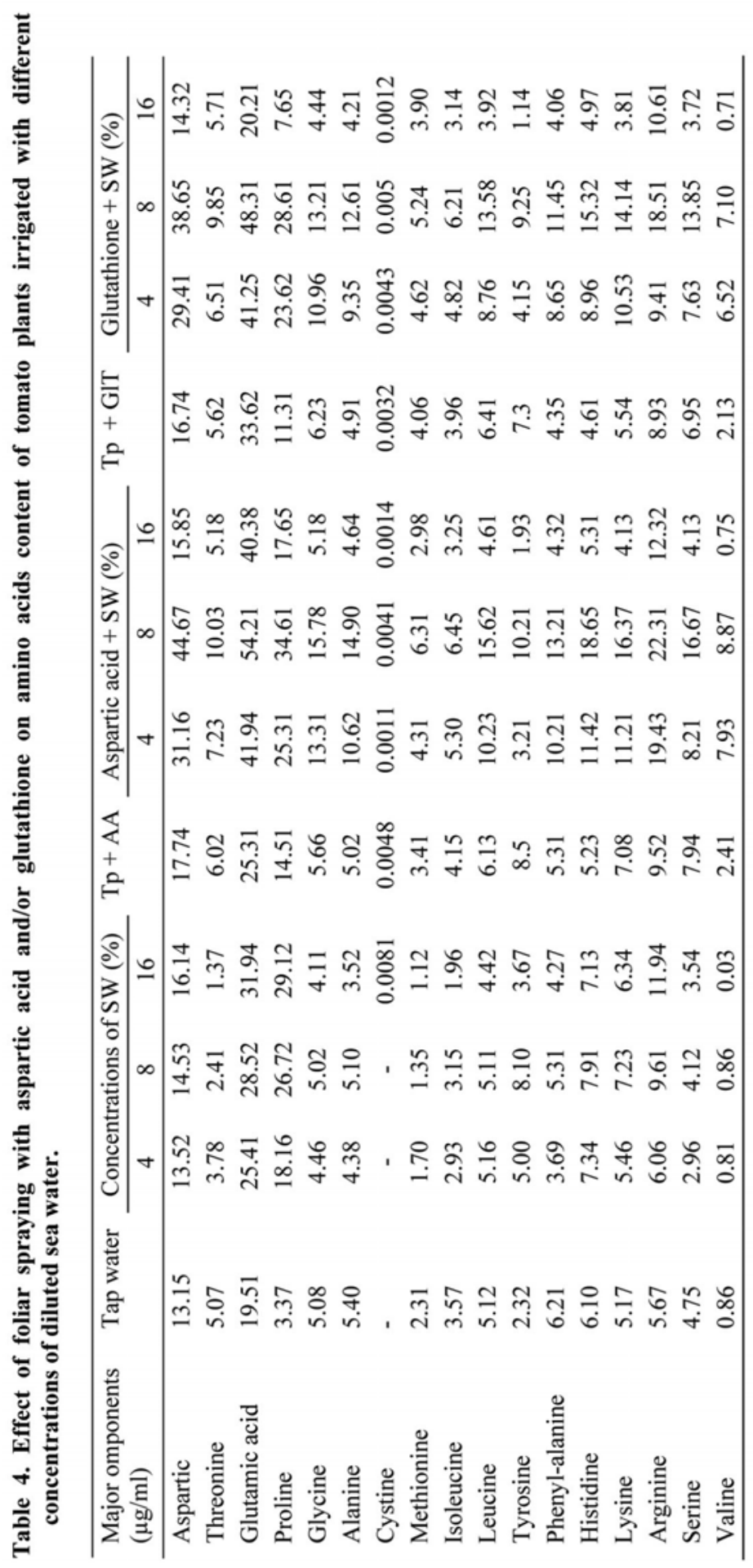


Salinity stress affected free amino acids in the shoot of tomato plants and the use of aspartic acid or glutathione showed a clear trend for amino acid constituent (Table 4). Results showed that different salinity levels led to reaccumulation of aspartic, glutamic, proline, histidine, and arginine, since these amino acids reached their maximum increasing under the highest saline concentration $(16 \%)$ whereas, tyrosine and lysine were increased at $8 \%$ salinity level compared to that of the

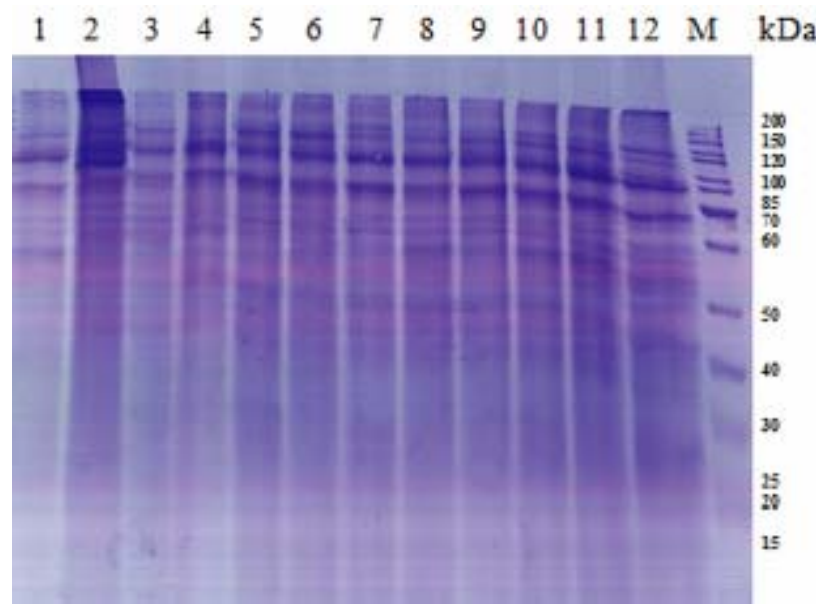

Fig. 4. Protein profile on SDS-PAGE of the leaves of tomato plants as influenced by foliar spray with aspartic acid or glutathione and grown under salinity stress. Where: $(\mathrm{M})=$ Marker protein ; $(1)=$ Control; $(2)=4 \%$ $\mathrm{SW} ;(3)=8 \% \mathrm{SW} ;(4)=16 \% \mathrm{SW} ;(5)=\mathrm{AA}+\mathrm{Tp} ;(6)=\mathrm{AA}+4 \% \mathrm{SW} ;(7)=\mathrm{AA}+8 \% \mathrm{SW} ;(8)=\mathrm{AA}+$ $16 \% \mathrm{SW} ;(9)=\mathrm{GlT}+\mathrm{Tp} ;(10)=\mathrm{GlT}+4 \% \mathrm{SW} ;(11)=\mathrm{GlT}+8 \% \mathrm{SW} ;(12)=\mathrm{GlT}+16 \% \mathrm{SW}$.
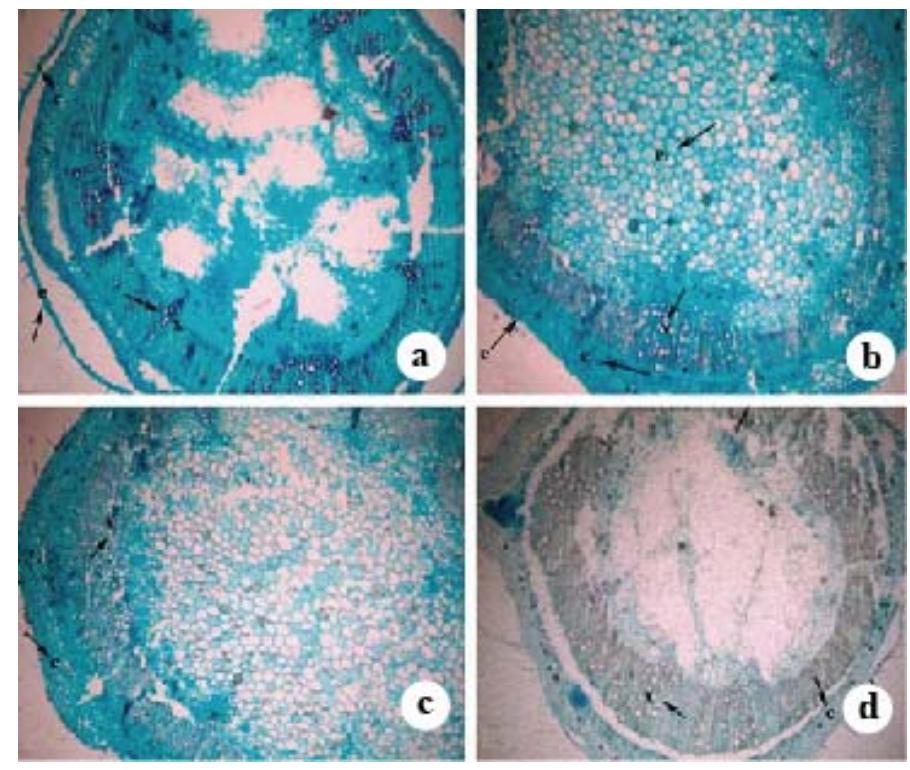

Fig. 5. Transverse sections of stem of tomato plants treated with diluted sea water concentrations; (a) Control (X40). (b) 4\% SW (X40). (c) $8 \% \mathrm{SW}$ (X40). (d) $16 \% \mathrm{SW}$ (X40). (e) epidermis, (c) cortex, (x) xylem, (Pi) pith. 
Table 5. Counts and measurements $(\mu \mathrm{m})$ of certain histological features in transverse section through the stem of tomato plant treated with aspartic acid and/or glutathione and grown under different concentrations of diluted sea water.

\begin{tabular}{|c|c|c|c|c|c|}
\hline Treatments & & $\begin{array}{c}\text { Stem } \\
\text { diameter }\end{array}$ & $\begin{array}{l}\text { Epidermis } \\
\text { thickness }\end{array}$ & $\begin{array}{l}\text { Cortex } \\
\text { thickness }\end{array}$ & $\begin{array}{c}\text { Xylem tissue } \\
\text { thickness }\end{array}$ \\
\hline \multirow[t]{4}{*}{ Sea water (SW) } & Tap water (Control) & 3475.00 & 12.00 & 310.80 & 145.00 \\
\hline & $4 \% \mathrm{SW}$ & 3581.50 & 12.50 & 350.25 & 160.00 \\
\hline & $8 \% \mathrm{SW}$ & 3187.00 & 11.00 & 250.50 & 125.00 \\
\hline & $16 \% \mathrm{SW}$ & 3050.00 & 10.25 & 225.90 & 110.50 \\
\hline \multirow[t]{4}{*}{ Aspartic acid (AA) } & $\mathrm{AA}+\mathrm{Tp}$ & 3940.5 & 13.00 & 430.25 & 187.50 \\
\hline & $\mathrm{AA}+4 \% \mathrm{SW}$ & 4125.00 & 14.00 & 470.50 & 250.00 \\
\hline & $\mathrm{AA}+8 \% \mathrm{SW}$ & 4200.00 & 14.75 & 480.00 & 280.00 \\
\hline & $\mathrm{AA}+16 \% \mathrm{SW}$ & 3825.00 & 13.00 & 410.00 & 170.50 \\
\hline \multirow[t]{4}{*}{ Glutathione (GlT) } & $\mathrm{GlT}+\mathrm{Tp}$ & 3662.00 & 13.00 & 400.00 & 165.00 \\
\hline & $\mathrm{GlT}+4 \% \mathrm{SW}$ & 4050.00 & 13.50 & 450.90 & 225.00 \\
\hline & $\mathrm{GlT}+8 \% \mathrm{SW}$ & 4125.00 & 14.00 & 462.50 & 225.00 \\
\hline & $\mathrm{GlT}+16 \% \mathrm{SW}$ & 3250.00 & 11.30 & 285.20 & 138.50 \\
\hline
\end{tabular}
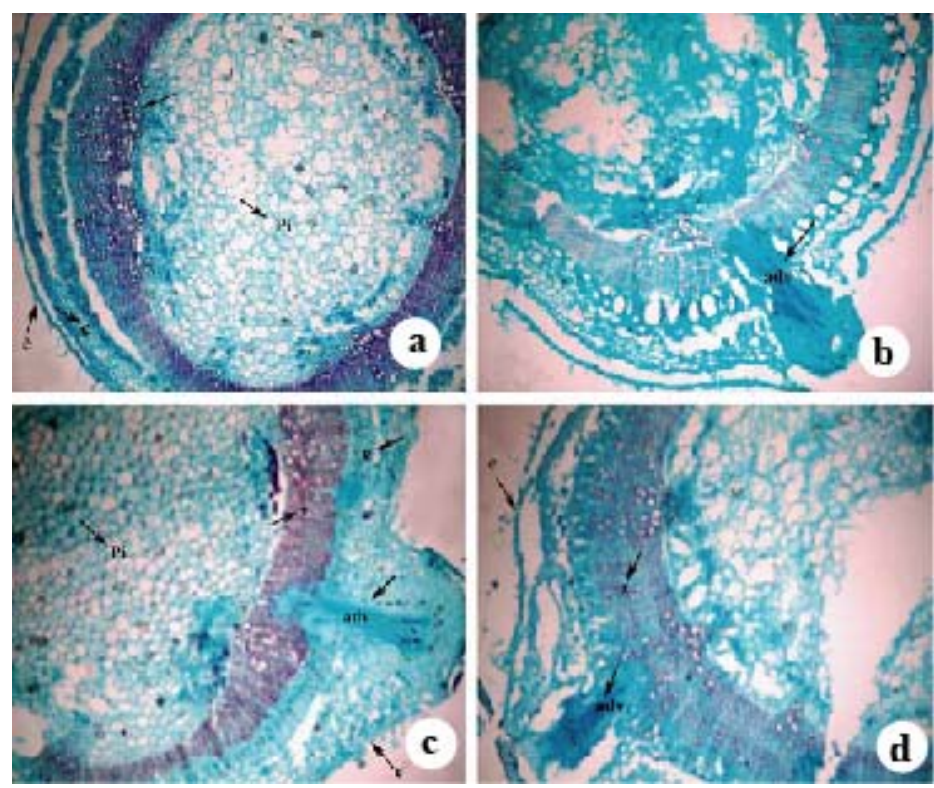

Fig. 6. Transverse sections of stem of tomato plants treated with aspartic acid and diluted sea water concentrations; (a) AA+Tp (X40). (b) $\mathrm{AA}+4 \% \mathrm{SW}$ (X40). (c) $\mathrm{AA}+8 \% \mathrm{SW}$ (X40). (d) $\mathrm{AA}+16 \% \mathrm{SW}$ (X40). (e) epidermis, (c) cortex, (x) xylem, (Pi) pith, (adv) adventitious root.

control. On the other hand, all the remaining amino acids were lowered by various salinity levels. In general, data in Table 4 indicated that all the amino acids were increased by spraying the plants with aspartic acid or glutathione under non saline or saline conditions compared with control. In addition, under 4 and $8 \%$ of saline condition, the treatment of AA or GIT increased all amino acids content particularly the contents of aspartic, glutamic acid, proline and arginine while the 
concentration of $16 \%$ decreased amino acids content compared with control. Amino acids represent one of the important classes of metabolites in the cell because they are the building blocks of proteins, which form the chemical basis necessary for life and have a many of roles in metabolism. Amino acids such as proline, asparagines and aminobutyric acid, play an important role in the osmotic adjustment of the plant under saline conditions (Mittler 2002). The accumulation of amino acids in plants exposed to stress probably attributed to the disturbance in amino acid metabolism (Hemmat 2007). Hassanein et al. (2008) indicated that arginine was the effective compound in increasing proline, total amino acid and protein contents of wheat plants under normal or stressed condition.
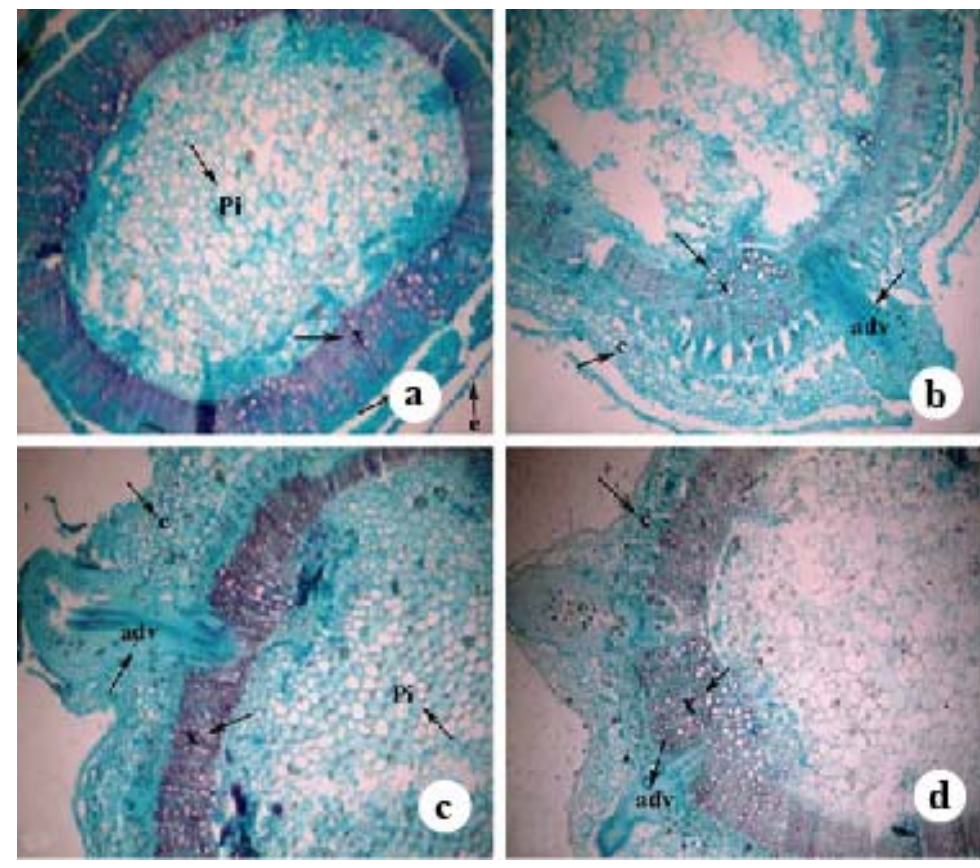

Fig. 7. Transverse sections of stem of tomato plants treated with glutathione and diluted sea water concentrations; (a) GlT+Tp (X40). (b) GlT+4\% SW (X40). (c) GlT+8\% SW(X40). (d) GlT+16\% SW(X40). (e) epidermis, (c) cortex, (x) xylem, (Pi) pith, (adv) adventitious root.

Salt stress decreased the stem diameter, epidermis cell size, cortex zone thickness, number of xylem vessels in plants irrigated with the highest concentration of sea water $(16 \%)$ in comparison with the control plants (Table 5 and Figs 5-7). On the other hand, spraying the plants with AA or GlT increased stem diameter, epidermis cell size, numbers of xylem vessels in comparison with the control plants. Moreover, application of AA and / or GlT at all different levels of salinity often caused obvious increase in the mentioned characters and the appearance of some adventitious roots which was observed only by using these amino acids accompanied by exposure the plants to salinity levels, since these adventitious roots were absent either in control plants or in plants treated with salinity only. Thus, amino acids treatment was mostly determined to have a successful performance in ameliorating the inhibitory effects of salinity on stem anatomy of tomato plants. The changes in stem anatomy of tomato plants caused by salinity stress appeared as a result of osmotic effect and the difficulty of water uptake from the saline soil. Reducing effects of salt stress on stem diameter, epidermis cell width, cortex zone thickness and xylem width were 
reported previously (Pimmongkol et al. 2002). The present study revealed that cortex zone thickness and epidermis cell width increased under saline conditions by treating the plants with aspartic acid or glutathione could fit with those obtained by Ali (2001) who found that application of ascorbic acid induced anatomical changes in the stem of two cultivars of tomato. He also indicated that ascorbic acid applications increased stem diameter and cortical layer thickness. The presence of some adventitious roots which produced from the stem in plants treated with AA or GlT and grown under saline conditions confirm that these amino acids increase the tolerance capacity of plants to overcome the saline conditions by increasing their ability to absorb more amounts of water.

\section{References}

Ali ZA 2001. Ascorbic acid induced anatomical changes in leaves and stems of tomato plants. Bull. NRC Egypt 26 (3): 371-382.

Apte SK and Bhagwat AA 1998. Salinity-stress-induced proteins in two nitrogen-fixating Anabaena strains differentially tolerant to salt. J. Bacteriol. 171: 909-15

Dash M and Panda SK 2001. Salt stress induced changes in growth and enzyme activities in germinating Phaselous mungo seeds. Biol. Plant 44: 587-589.

El-Bassiouny HM, Mostafa HA, El-Khawas SA, Hassanein RA, Khalil SI, Abd El-Monem AA 2008. Physiological responses of wheat plant to foliar treatments with arginine or putrescine. Aust. J. Basic Appl. Sci. 2(4): 1390-1403.

Garcia GD, Ferreira PA, Miranda GV, Neves JC, Moraes WB and Santos DB 2007. Leaf contents of cationic macronutrients and their relationships with sodium in maize plants under saline stress. IDESIA 25: 93-106.

Gehrke CW, Wall LL, Absheer JS, Kasier FE and Zumwalt W 1985. Sample preparation for chromatography of amino acids: acid hydrolysis of proteins. J. Assoc. Anal. Chem. 68-81.

Hassanein RA, Khalil SI, El-Bassiouny HM, Mostafa HA, El-Khawas SA and Abd El-Monem AA 2008. Protective role of exogenous arginine or putrescine treatments on heat shocked wheat plant. $1^{\text {st }}$ International Conference on Biological and Environmental Sciences, 13-16 March, Hurghada, Egypt.

Hemmat K 2007. Role of glutathione and polyadenylic acid on the oxidative defense systems of two different cultivars of canola seedlings grown under saline condition. Aust. J. Basic Appl. Sci. 1(3): 323-334.

Hernandez J, Jimenez A, Mullineaux P and Sevilla FN 2000. Tolerance of pea plants (Pisum sativum) to long-term salt stress is associated with induction of antioxidant defences. Plant Cell Environ. 23: 853862.

Krizek DT, Kramer GF, Upadhyaya A and Mirecki RM 1993. UV-B response of cucumber seedling grown under metal halid and high pressure sodium/deluxe lamps. Plant Physiol. 88: 350-358.

Kumar KB and Khan PA 1982. Peroxidase and polyphenol oxidase in excised ragi (Eleusine coracana cv. PR 202) leaves during senescence. Indian J. Exp. Bot. 20: 412-416.

Laememli UK 1970. Cleavage of structure proteins during the assembly of the head of bacteriophageT4. Nature 227: 680-685.

Mitsuya S, Takeoka Y and Miyake H 2000. Effects of sodium chloride on foliar ultrastructure of sweet potato (Ipomoea batatas Lam.) plantlets grown under light and dark conditions in vitro. J. Plant Physiol. 157: 661-667.

Mittler R 2002. Oxidative stress, antioxidants and stress tolerance. Trends in Plant Sci. 7: 405-410.

Mukherjee SP and Choudhuri MA 1983. Implications of water stress-induced changes in the levels of endogenous ascorbic acid and hydrogen peroxide in Vigna seedlings. Plant Physiol. 58: 166-170.

Nassar MA and El-Sahhar KF 1998. Botanical preparations and Microscopy (Microteqnique) Academic Bookshop, Dokki, Giza, Egypt. pp. 219

Philip B, Bernard L and William H 1954. Vitamins and Deficiency Diseases, In: Practical Physiological Chemistry, McGraw-Hill company, INC. New York, Toronto, London 1272-1274. 
Pimmongkol A, Terapongtanakhon S and Udonsirichakhon K 2002. Anatomy of salt- and non-salt-tolerant rice treated with $\mathrm{NaCl}$. In: $28^{\text {th }}$ Congr. Science and Technology of Thailand, Bangkok, Thailand.

Rawia AE, Lobna ST and Soad MI 2011. Alleviation of Adverse Effects of Salinity on Growth, and Chemical Constituents of Marigold Plants by Using Glutathione and Ascorbate. J. Appl. Sci. Res. 7(5): 714-721.

Sairam RK, Srivastava GC, Agarwal SA and Meena RC 2005. Differences in antioxidant activity in response to salinity stress in tolerant and susceptible wheat genotypes. Biol. Plant 49: 85-91.

Wahba H, Mohamed SM, Attoa GE and Farahat AA 2002. Response of Antholyza aethiopica to foliar spray with some amino acids and mineral nutrition with sulphur. Ann. Agric. Sci. 47: 929-944.

(Manuscript received on 10 November, 2012; revised on 26 January, 2013) 